\title{
Rapid Waste Composition Studies for the Assessment of Solid Waste Management Systems in Developing Countries
}

\section{Max J Krause and Timothy G Townsend}

Environmental Engineering Sciences, University of Florida, Gainesville, FL 32611, USA

*Corresponding author: Timothy G Townsend, Environmental Engineering Sciences, University of Florida, Gainesville, FL 32611, USA, Tel: (352) 392-0846; Fax: (352) 392-3394; E-mail: ttown@ufl.edu

Received date: March 28, 2014; Accepted date: May 05, 2014; Published date: May 12, 2014

Copyright: (C2014 Townsend TG, et al. This is an open-access article distributed under the terms of the Creative Commons Attribution License, which permits unrestricted use, distribution, and reproduction in any medium, provided the original author and source are credited.

\begin{abstract}
A methodology for the rapid assessment of waste composition was assessed by examining municipal solid waste from five rural communities throughout Central America and the Caribbean. Target waste components were minimized and a sieve-shaker table was employed to maximize the quantity of waste that could be sorted in an efficient and timely manner. Food waste (along with other fine materials) was the largest component by weight, but plastics represented a major fraction. To illustrate potential utility of composition study results, the data were used to estimate the methane generation potential, $L_{0}$, of each municipality's waste stream. While the approach does not provide the statistical rigor of more standardized waste composition methodologies, the technique does provide a tool for rapid assessment of local waste characteristics.
\end{abstract}

Keywords: Waste composition; Food waste; Landfill; Central America; Haiti; Methane potential

\section{Introduction}

Adequate solid waste management systems (SWMS) have lagged in developing countries behind other infrastructure needs. Rural municipalities, in particular, do not have the resources to construct and maintain the infrastructure that supports the use of conventional waste collection vehicles. While rural municipalities are often legally responsible for municipal solid waste (MSW) collection for all residents, the burden often falls to informal businesses. Without formal contracts or established liabilities, collectors often dispose of the waste wherever they can $[1,2]$. In many cases, an unmanaged dump site is established over several years or decades. While this creates a single, isolated source of pollution, it also concentrates the liquid and gaseous emissions. Furthermore, as technology advances and social habits change, waste composition changes. Whereas most of the waste dumped twenty years ago in rural areas may have been predominantly organic and biodegradable, the proliferation of plastics, electronics, and other environmentally persistent materials within current waste streams warrant modern SWMS.

To address the problems posed from sub-standard waste disposal, rural communities are often urged to implement more sustainable SWMS, both by national regulations and by outside parties. Challenges to implementing more sustainable practices include limited financial resources and the need to match an appropriate technology to the region's specific waste characteristics. Accurate waste composition data can be a crucial tool for selecting an appropriate waste management approach; the relative fractions of food waste, plastics, metals, and other components dictate the viability of technologies such as composting, anaerobic digestion, thermal energy recovery, and recycling. Such data are often lacking in developing countries [3-6], and even rarer in rural areas $[7,8]$. The cost and nature of the studies can be prohibitive to small and local governments, as they are typically performed over a period of multiple days or weeks, and sampling events are repeated throughout the year [9-11]. The largest direct cost of a composition study is attributed to labor, which typically requires 4 to 12 operators as well as a supervisor $[9,12]$.

The work presented in this paper was motivated by challenges the authors faced as part of several efforts providing assistance to rural communities on waste management issues. Some estimate of the composition of the local waste stream was desired, but time and resources were not available for a complete waste composition study. Over several trips, a protocol was developed that allowed a quick evaluation of a municipality's waste stream in a single sampling event. A description and assessment of this procedure are presented within to provide benefit to others interested in similar activities. Results of composition studies from Costa Rica, Guatemala, Haiti, and Honduras are described, and the utility of the results are illustrated by estimating the MSW methane potential, $\mathrm{L}_{0}\left(\mathrm{~m}^{3} \mathrm{CH}_{4} / \mathrm{Mg}\right.$ MSW $)$ of the different communities and through evaluating the occurrence of plastics in each waste stream. Other challenges with respect to waste collection and management in the subject communities are also discussed to provide a broader context of issues to the reader.

\section{Materials and Methods}

\section{Site Descriptions}

Rapid waste composition studies were performed on six waste streams in five rural towns across Central America from 2010 to 2013 as part of an on-going effort by the authors to assess current waste management practices in developing countries and assist local communities. As illustrated in Figure 1, the locations included Nosara, Costa Rica; Tactic and San Juan Chamelco, Guatemala; Cabaret, Haiti; and Villa de San Francisco, Honduras. The waste streams examined in the study were market or residential waste as indicated in Table 1 . The local markets were the primary sources of commerce within the communities. As such, large amounts of waste were generated weekly at these central locations. 


\begin{tabular}{|l|l|l|l|}
\hline Town & Country & Waste Stream & Site ID \\
\hline Cabaret & Haiti & Market waste & CAB \\
\hline $\begin{array}{l}\text { San Juan } \\
\text { Chamelco }\end{array}$ & Guatemala & Market waste & SJM \\
\hline $\begin{array}{l}\text { San Juan } \\
\text { Chamelco }\end{array}$ & Guatemala & Residential & SJR \\
\hline Tactic & Guatemala & Residential & TAC \\
\hline Nosara & Costa Rica & Residential & NOS \\
\hline $\begin{array}{l}\text { Villa de San } \\
\text { Francisco }\end{array}$ & Honduras & Residential & VSF \\
\hline
\end{tabular}

The objectives of the waste sorts for each location were similar. The amount of organic matter subject to biological decomposition was of interest; this material could contribute to methane gas production when placed in a landfill and would be amenable to treatment via composting or anaerobic digestion. A second interest was an assessment of potential recovered resources (recyclable materials) present, as well as possible materials of concern (hazardous wastes); some materials offer real economic value, while other materials may have potential for pollution [13].

\section{Rapid waste composition methodology}

A standard method for waste composition analysis currently exists and additional guidelines have been established and published [9-12]. Generally, a representative sample of waste $(90-140 \mathrm{~kg})$ is taken from a collection truck and manually sorted into several categories (e.g., plastics) and subcategories (e.g., polyethylene terephthalate, PET). A great number of different waste categories are often sorted. The components are weighed and the relative fractions of waste are determined from the combined weight of the total waste sample. Samples from a large number of waste collection vehicles are sorted, with the number of samples based on statistical calculations that consider the components being categorized and the desired confidence level [9].

In the current study, a methodology was needed to provide a general sense of the waste stream components in a relatively short period of time. Goals included processing a relatively large amount of waste into a few basic categories. To assist in this objective, a sieveshaker table was constructed at each location with dimensional lumber and a sliding, wire mesh top for categorizing waste components. The tables were approximately $2 \mathrm{~m}$ by $1 \mathrm{~m}$ by $1 \mathrm{~m}$ (length by width by height) with the surface of the table consisting of steel mesh layer (square grid sizes of approximately $6.5 \mathrm{~cm}^{2}\left(1 \mathrm{in}^{2}\right)$; see Figure 2). The mesh table was designed to slide back and forth to agitate the waste sample, maximizing the amount of material that passed through the sieve; fine materials less than size of the mesh fell through the table surface onto a plastic tarp. The objective of the screening operation was to quickly remove small pieces that were difficult and timeconsuming to categorize; these materials often did not represent components of particular value for resource recovery. The fine fraction was visually assessed to estimate an organic content; it was not sorted and was weighed in bulk. This reduced the amount of time required per waste load and allowed for greater amounts of waste to be sorted throughout the day.

Loads were sorted into six to nine categories as shown in Table 2 and weighed to the nearest $0.5 \mathrm{~kg}$. Biodegradable and inert categories were chosen based on the need to have distinct, uniquely identifiable categories while also being inclusive of common and uncommon materials. "Plastics" incorporated resin codes 1 to 7 for both rigid and film plastics. "Food waste" consisted of both food and soiled paper that would not be suitable for recycling. If an item was not immediately identifiable, it was placed in the "Other" category. The amount of time for sampling did not allow for critical sub-categorization, however, site-specific categories were created if one particular waste component was found in significant quantity. 


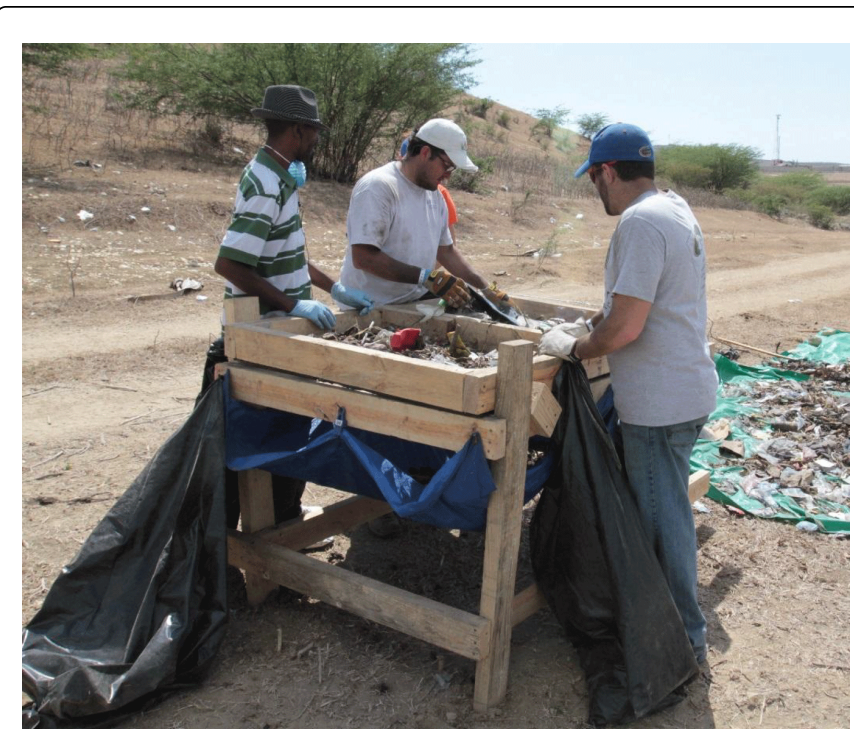

Figure 2: The sieve-shaker table designed and used for rapid waste composition studies.

\begin{tabular}{|l|l|}
\hline Biodegradable Fraction & Inert Fraction \\
\hline Paper Products & Plastics \\
\hline Food waste & Metals \\
\hline Rubber, Leather, and Textiles & Glass \\
\hline Yard waste & Other \\
\hline Wood & \\
\hline
\end{tabular}

Table 2: Waste categories of a rapid waste composition study.

Garbage bags were selected at random from the truck or landfill stockpile. Bags were opened onto a receiving tarp and waste was spread out to first look for hazardous components. Once the waste was deemed free of hazards by the supervisor, waste sorters would add waste to the sieve-shaker table. After shaking, waste was sorted from the table and placed into new garbage bags. Once a bag was filled with a single component it was closed and weighed. Categorized samples were weighed in bags with hanging scales (range 0 to $40 \mathrm{~kg}$ ). The weight was recorded in the respective waste category and a new bag was designated for that category. Researchers were able to sort 250 to $780 \mathrm{~kg}$ of waste in a single day, the maximum allotted time for waste characterization.

Maintaining well-trained labor is always a concern for waste composition studies [9]. Waste sorters must be aware of the target categories to avoid contamination and erroneous results. Safety is another major concern. In this study, all sorters wore rubber and textile gloves over waterproof nitrile gloves. Long pants and longsleeve shirts were recommended as wells as hats to protect from the sun. Sorters also wore safety glasses and, in some cases, dust masks.

\section{Methane Potential of MSW}

Waste composition data are useful for the development of accurate greenhouse gas (GHG) inventories and life-cycle assessments of
SWMS [14,15]. Landfills are a major contributor to GHG emissions and dumping is the most common method of waste disposal in Central America [16]. Unmanaged dumps emit much of the generated methane into the atmosphere, unlike sanitary landfills that incorporate regular cover soil and gas collection and control systems for treatment or energy recovery. To illustrate the utility of the waste composition study results, the $\mathrm{L}_{0}$ of each community's waste stream was estimated. The US EPA landfill gas production model requires the assumption of an ultimate methane potential, $\mathrm{L}_{0}\left(\mathrm{~m}^{3} \mathrm{CH}_{4} / \mathrm{Mg}\right.$-MSW $)$, of the waste [17]. Past research has reported the methane potential of individual waste components (measured using laboratory experiments) [18-20] and others have coupled these data with composition study results to estimate a $L_{0}$ value for a specific waste stream [21,22]. In the present study, methane potential data from Owens and Chynoweth [19] and Jeon et al. [20] were used with the composition results to estimate $\mathrm{L}_{0}$ for each community's waste stream.

\section{Results and Discussion}

\section{Rapid waste composition studies observations}

Because municipal participation in waste collection is not mandatory, it was thought that not all sources of waste generation would be captured by the rapid composition studies. Field observations were made during waste collection and disposal at all locations to determine if waste streams other than MSW were entering the landfill. Dump site assessments were conducted in each of the towns. In most cases, the dumping areas had developed over decades, with the site being selected based on proximity to the municipality and availability rather than engineering criteria.

Because much of the garbage sorted in Haiti was previously burned before disposal at the dump site, the fines collection tarp required weighing several times. When the fines collection tarp was being weighed, all sorting was required to pause until the tarp could be emptied and replaced in order to ensure all fines were collected from the table. Thus, in cases where fine material is abundant, the sorting process may be slowed because of frequent re-weighing of the collection tarp. However, the minimization of categories helps to offset the time attributed to identifying waste components and any such breaks in sorting activity.

Worker safety was paramount during waste composition studies. Sorters were outfitted with safety equipment to prevent ingestion, inhalation, or dermal contact of waste materials. In Central America particularly, the heat and sun are of concern as well. Because the studies rely on obtaining fresh MSW samples, at times the collection trucks would not arrive on site until mid-morning. Thus, the majority of the sorting took place through midday and the afternoon. Worker fatigue posed a challenge to productivity and multiple breaks were provided throughout the day; water was made available to sorters at all times.

The ability to complete the study in a single day significantly lowered the cost of the research. For these composition studies, many of the sorters were student volunteers. If additional laborers were required they were compensated with approximately $\$ 20$ USD/day, higher than the average daily wage in any of these countries. Table 3 itemizes the costs of a rapid waste composition study, including materials and labor. This is significantly less than typical composition studies [9]. 


\begin{tabular}{|l|l|l|l|l|}
\hline \multirow{2}{*}{\multicolumn{2}{|c|}{ Item }} & \multicolumn{3}{c|}{ USD (\$) } \\
\cline { 3 - 5 } & Cost & Quantity & Total \\
\hline \multirow{4}{*}{ Table } & lumber & $\$ 80$ & 1 & $\$ 80$ \\
\cline { 2 - 5 } & $2 \mathrm{~m} \times 1 \mathrm{~m}$ mesh & $\$ 20$ & 1 & $\$ 20$ \\
\cline { 2 - 5 } & $6 \mathrm{~cm}$ nails (pack) & $\$ 5$ & 1 & $\$ 5$ \\
\cline { 2 - 5 } & $3 \mathrm{~m} \times 2 \mathrm{~m}$ tarp & $\$ 20$ & 2 & $\$ 40$ \\
\hline \multirow{5}{*}{ Labor } & & $\$ 20$ & 8 & $\$ 160$ \\
\hline \multirow{5}{*}{ Materials } & Work gloves & $\$ 12$ & 4 & $\$ 48$ \\
\cline { 2 - 5 } & Nitrile gloves & $\$ 18$ & 4 & $\$ 72$ \\
\cline { 2 - 5 } & Safety glasses & $\$ 6$ & 10 & $\$ 60$ \\
\cline { 2 - 5 } & Dust masks & $\$ 36$ & 1 & $\$ 36$ \\
\cline { 2 - 5 } & Garbage bags (pack) & $\$ 25$ & 2 & $\$ 50$ \\
\cline { 2 - 5 } & $\begin{array}{l}\text { Hanging scales }(0-40 \\
\text { kg) }\end{array}$ & $\$ 12$ & 2 & $\$ 24$ \\
\hline Total & & & & $\$ 595$ \\
\hline
\end{tabular}

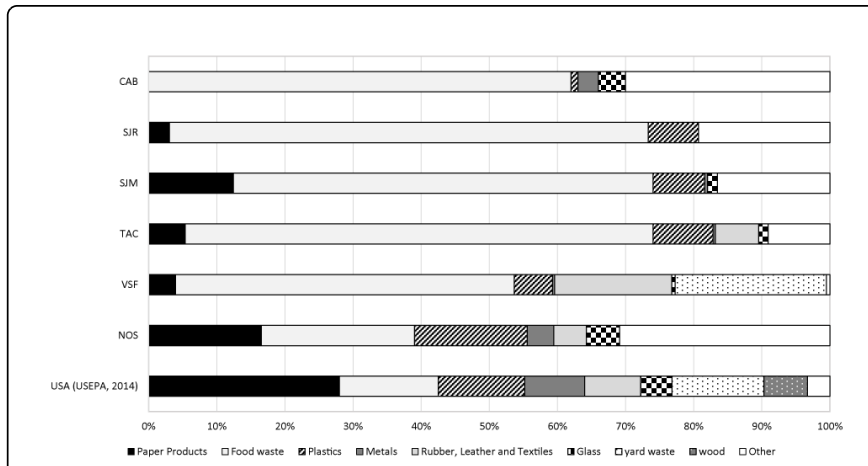

Figure 3: Waste composition data from 5 rural towns (6 waste streams) and the United States for comparison.

Small, light-weight items (less than $6.5 \mathrm{~cm}^{2}\left(1 \mathrm{in}^{2}\right)$ ) would not typically be targeted as a recoverable commodity at a waste recovery operation, other than potentially being included as part of the biologically treated waste fraction (i.e., that destined for composting or anaerobic digestion). The sieve-shaker table allowed for maximum sorting efficiency of bulky or heavy material while allowing residual pieces to fall through to a collection tarp below. The fines were grouped into a single category that was visually assessed, weighed and initially categorized separately. Generally, the fine fraction was found to be highly organic (food scraps) or soil-like in nature (dust, street sweepings) and were subsequently added to the "Food waste" category. Small non-biodegradable items, such as bottle caps, were determined to be negligible to the total weight of the "Fines" category.

As expected, many types of plastics (resin codes 1 to 7) were found within the waste streams. Plastics contributed $17 \%$ of the weight to the waste stream of Nosara, but only $7 \%, 8 \%, 9 \%, 6 \%$, and $0.4 \%$ to San Juan Chamelco residential, San Juan Chamelco market, Tactic, Villa de San Francisco, and Cabaret, respectively. The amount of plastic measured by weight in Nosara, Costa Rica during this study was higher than the estimated plastic fraction of the US waste stream [24]. Again, this can be attributed to the tourists that frequent the area, consuming and discarding single-use plastic bottles and bags. Because plastics are much less dense than other items such as cardboard, or food waste, the $17 \%$ by weight constitutes a considerable volume fraction of the waste stream.

Large amounts of PET drink containers were observed in all waste streams. PET is a valuable recyclable commodity and was weighed separately during the composition studies. In Guatemala, a significant fraction of polystyrene was found during the study. It was categorized and weighed separately and subsequently included in the "Plastics" category. Plastic film was common in most of the waste streams and many of the large garbage bags contained smaller bags of waste. This was later found to be a method of preventing vectors from being attracted to waste that was stored in a home or building that lacked air conditioning.

The largest product category of US MSW is "Containers and Packaging," which includes paper and plastic [24]. It was hypothesized that the percentage of plastics in a waste stream would relate to a country's economic status. The percentage of plastics found within the waste stream was compared to the gross domestic product purchase power parity (GDP PPP) per capita of the respective countries [25]. A trend was found that shows a direct relationship between GDP per 
Page 5 of 6

capita and the fraction of plastic within the waste stream (See Figure 4). Two additional studies examining household waste composition in rural Mexico [7] and Serbia [5] were included to better assess this trend. The trend line does not include the US datapoint, which is the US EPA's national average, not specifically rural generation [24].

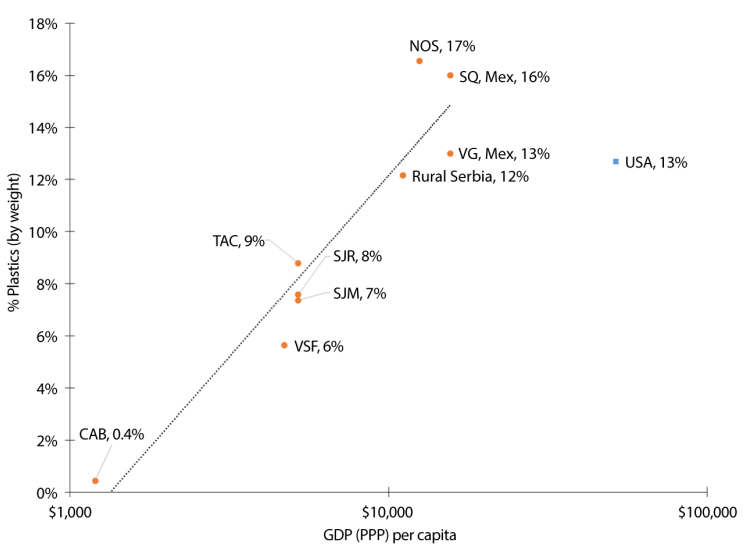

Figure 4: Percentage of plastics found within a rural waste stream compared to the country's GDP per capita.

\section{Calculation of methane emissions from waste composition data}

The $\mathrm{L}_{0}$ of each waste stream was calculated using componentspecific data and are presented in Table 4. Calculated methane potentials of the waste streams ranged from 72 to $104 \mathrm{~m}^{3} \mathrm{CH}_{4} / \mathrm{Mg}$, within the range of default values given in the US EPA's Central America Landfill Gas Model [17] and similar to the US default value (100 $\mathrm{m}^{3} \mathrm{CH}_{4} / \mathrm{Mg} \mathrm{MSW}$ ) [26]. Machado et al. [21] calculated $\mathrm{L}_{0}$ for fresh waste and excavated landfill samples from Brazil, determining L0 of that site to be $67 \mathrm{~m}^{3} \mathrm{CH}_{4} / \mathrm{Mg}$ MSW. $\mathrm{L}_{0}$ is dependent of the biodegradable fraction of MSW, but it is also dependent of moisture content because it is a volume per "as-received" mass coefficient. Food waste can be largely made of water, which contributes to the weight of the waste, but does not contribute to methane potential. Paper products have high volatile solids and low moisture contents, which could increase the methane potential of that waste stream, as shown in Table 4. Haiti, having the second highest food waste fraction, had the second lowest methane potential, $73 \mathrm{~m}^{3} \mathrm{CH}_{4} / \mathrm{Mg} \mathrm{MSW}$. This was largely attributed to the difficulties in obtaining fresh MSW samples before they were burned. Partially burned samples were taken multiple times throughout the day, but in all samples, some portion of the waste had already been combusted. Better coordination with the local waste haulers would be needed to better represent unburned MSW.

\begin{tabular}{|l|l|l|l|l|l|l|}
\hline \multirow{2}{*}{ Site ID } & \multirow{2}{*}{ Country } & \multicolumn{4}{|l|}{ Percent by weight of waste stream (\%) } & $\mathbf{L}_{0}$ \\
\cline { 3 - 7 } & $\begin{array}{l}\text { Paper } \\
\text { Products }\end{array}$ & $\begin{array}{l}\text { Food } \\
\text { Waste }\end{array}$ & $\begin{array}{l}\text { Rubber, } \\
\text { Leather, } \\
\text { and } \\
\text { Textiles }\end{array}$ & $\begin{array}{l}\text { Yard } \\
\text { Waste }\end{array}$ & $\begin{array}{l}\left(\mathbf{m}^{3} \quad \mathbf{C H}_{4} /\right. \\
\mathbf{M g} \mathbf{~ M S W})\end{array}$ \\
\hline CAB & Haiti & 0 & 62 & 0 & 0 & 73 \\
\hline SJR & Guatemala & 3 & 70 & 0 & 0 & 90 \\
\hline SJM & Guatemala & 12 & 62 & 0 & 0 & 102 \\
\hline
\end{tabular}

\begin{tabular}{|l|l|l|l|l|l|l|}
\hline TAC & Guatemala & 5 & 69 & 6 & 0 & 101 \\
\hline NOS & Costa Rica & 17 & 22 & 5 & 0 & 72 \\
\hline VSF & Honduras & 4 & 50 & 17 & 22 & 104 \\
\hline
\end{tabular}

Table 4: The methane potential, $\mathrm{L}_{0}$, of 6 Central American waste streams based on waste composition data.

\section{Conclusions}

Rapid waste composition studies were performed on waste from five rural communities in Costa Rica, Guatemala, Haiti, and Honduras. Time and resource constraints did not permit an extensive waste composition study as might be typical in developed countries, but some general characterization of the waste was needed. The protocol described herein provides a means for interested parties to collect waste composition data in a single sampling event. By characterizing only a limited number of categories (six to nine) and using a shaker-table to quickly screen out difficult to identify components, the methodology allows for rapid data collection while also providing valuable information regarding relative amounts of biodegradable waste, recyclable materials, and components destined for landfill. Observations of collection and disposal sites indicated that the waste collected for the studies was representative of the overall waste stream.

Food waste (plus fines) accounted for $50 \%$ or greater of the waste streams in San Juan Chamelco, Tactic, Cabaret, and Villa de San Francisco. Paper and plastics were significant fractions but varied by location. Nosara was found to have notably greater percentage of plastics $(17 \%)$ - this was attributed to single-use bags and bottles. To illustrate the utility of the waste composition data, the results were coupled with component-specific methane yield data to estimate sitespecific $\mathrm{L}_{0}$ values; the results fell within the default ranges for each country in the US EPA's landfill emission model (Haiti is not included in the model). A direct relationship was found between the percentage of plastics within the waste stream and a country's per capita GDP. This may be of value to other municipalities that lack waste composition data, but are interested in enacting a recycling program for plastics. Some plastics have a high value in the recycling markets, but many of the films and other packaging materials lack viable recycling markets and will be landfilled.

Some valid concerns of the proposed methodology remain. A single sampling event cannot replace a full, long-term waste composition study. This study does not consider sample sizes and only considers the total amount of waste that can be sorted in a single day. Seasonal variations cannot be accounted for without additional data. The sampling event could be supplemented by information from the municipality or waste hauler to extrapolate waste generation rates. While uncertainty exists within any waste composition study, these data serve to inform the municipalities, the public, and researchers in geographic areas where such data do not exist, and allow more informed decision-making regarding solid waste management in developing countries.

\section{Acknowledgements}

This work was made possible by the students of the Solid and Hazardous Waste Management Capstone courses (2010-2013) as well as donations from private parties, including HDR, Jacobs Engineering, 
Citation: Max J Krause and Timothy G Townsend (2014) Rapid Waste Composition Studies for the Assessment of Solid Waste Management Systems in Developing Countries. Int J Waste Resources 4: 145. doi:10.4172/2252-5211.1000145

Page 6 of 6

Golder Associates, Jones Edmunds and Associates, $\mathrm{CH}_{2} \mathrm{MHill}$, and Koogler \& Associates. The authors would like to recognize Antonio Yaquian-Luna for his contribution to this work. The authors would also like to acknowledge the continued support of the University of Florida Engineering School of Sustainable Infrastructure and Environment.

\section{References}

1. Guerrero LA, Maas G, Hogland W (2013) Solid waste management challenges for cities in developing countries. Waste Manag 33: 220-232.

2. Yeomans JC (2008) Development of an Integrated Waste Management Plan for Ordinary Solid Waste in Rural Communities in Latin America. Tierra Tropical 4: 1-25.

3. UN-Habitat (2011) Collection of Municipal Solid Waste Key issues for Decision-makers in Developing Countries. UN-HABITAT Nairobi 38.

4. Badgie D, Samah M, Manaf L (2012) Assessment of Municipal Solid Waste Composition in Malaysia: Management Practice and Challenges. Polish Journal of Environmental Studies 21: 539-547.

5. Vujic G, Jovicic N, Redzic N, Jovicic G, Batinic B. et al. (2010) A fast method for the analysis of municipal solid waste in developing countries - case study of Serbia.Environmental Engineering and Management Journal 9: 1021-1029.

6. Henry RK, Yongsheng Z, Jun D (2006) Municipal solid waste management challenges in developing countries--Kenyan case study. Waste Manag 26: 92-100.

7. Taboada-González P, Armijo-de-Vega C, Aguilar-Virgen Q, OjedaBenítez S (2010) Household solid waste characteristics and management in rural communities. The Open Waste Management Journal 3: 167-173.

8. Laines Canepa JR, Zequeira Larios C, Valadez Treviño MEM, Garduza Sánchez DI (2012) Basic diagnosis of solid waste generated at Agua Blanca State Park to propose waste management strategies. Waste management and Research, 30: 302-310.

9. McCauley-Bell P, Reinhart DR, Sfeir H, Ryan BO (1997) Municipal Solid Waste Composition Studies. Practice Periodical of Hazardous Toxic and Radioactive Waste Management 1: 158-163.

10. Dahlén L, Lagerkvist A (2008) Methods for household waste composition studies. Waste Manag 28: 1100-1112.

11. ASTM International (2008) ASTM D5231 - 92(2008) Standard Test Method for Determination of the Composition of Unprocessed Municipal Solid Waste. ASTM International Conshohocken PA.
12. Sfeir H, Reinhart DR, McCauley-Bell PR (1999) An Evaluation of Municipal Solid Waste Composition Bias Sources. Journal of the Air \& Waste Management Association 49: 1096-1102.

13. Ojeda-Benítez S, Aguilar-Virgen Q, Taboada-González P, Cruz-Sotelo SE (2013) Household hazardous wastes as a potential source of pollution: a generation study. Waste Manag Res 31: 1279-1284.

14. Finnveden G, Johansson J, Lind P, Moberg A (2005) Life cycle assessment of energy from solid waste part 1: general methodology and results. Journal of Cleaner Production 13: 213-229.

15. US EPA (2006) Solid Waste Management and Greenhouse Gases. A LifeCycle Assessment of Emissions and Sinks (3 edtn).

16. World Bank (2012) What a Waste: A Global Review of Solid Waste Management.

17. US EPA (2007) User's Manual Central America Landfill Gas Model Washington DC.

18. Eleazer WE, Odle WS, Wang YS, Barlaz MA (1997) Biodegradability of Municipal Solid Waste Components in Laboratory-Scale Landfills. Environmental Science and Technology 31: 911-917.

19. Owens J, Chynoweth DP (1993) Biochemical methane potential of municipal solid waste (MSW) components. Water Science and Technology 27: 1-14.

20. Jeon EJ, Bae SJ, Lee DH, Seo DC, Chun SK, et al. (2007) Methane generation potential and biodegradability of MSW components. Sardinia 2007 Eleventh International Waste Management and Landfill Symposium Cagliari Italy.

21. Machado SL, Carvalho MF, Gourc JP, Vilar OM, do Nascimento JC (2009) Methane generation in tropical landfills: simplified methods and field results. Waste Manag 29: 153-161.

22. Cho HS, Moon HS, Kim JY (2012) Effect of quantity and composition of waste on the prediction of annual methane potential from landfills. Bioresour Technol 109: 86-92.

23. Kim SK, Lee T (2009) Degradation of lignocellulosic materials under sulfidogenic and methanogenic conditions. Waste Manag 29: 224-227.

24. US EPA (2014) Municipal Solid Waste Generation, Recycling and Disposal in the United States: Facts and Figures for 2012. 2012 MSW Characterization Reports.

25. CIA (2013) Country comparison GDP (purchasing power parity). The World Factbook.

26. US EPA (1998) Municipal Solid Waste Landfills. Compilation of Air Pollutant Emission Factors. Stationary Point and Area Sources (AP-42). US EPA, Research Triangle Park NC. 